\title{
The Effect of Creativity Model for Creativity Development in Teachers
}

\author{
Afzal Sadat Hosseini
}

\begin{abstract}
This paper addresses creativity as an educational approach, reviews the related theories and patterns of creative learning, and deals with teaching creativity to teachers generally, and Iranian teachers specifically. This idea has been proposed and studied by the researcher. The main focus of this program is the pattern of creativity development, in which five basic aspects of teacher performance have been dealt with: contextual-social, affective-cognitive, mental, educational, and physical aspects.

A part of this study deals with the effect of the program and the pattern of creativity development on teachers' skills. Data analysis by $T$-test for this quasi-experimental research indicated the positive effect of the program and led to the confirmation of the research hypothesis. Feedback from the teachers regarding their change of performance in the classroom, in spite of the passing of several years, indicates that they made positive use the pattern. All the teachers participating in the course stated that attending the course helped them to move away from teacher-centered toward learner-centered classes, which has made their students very enthusiastic.
\end{abstract}

Index Terms-Creativity, education, teachers' skills, experimental research.

\section{INTRODUCTION}

The importance and necessity of creativity and its ever-developing process in the present time has attracted the attention of researchers and educational planners towards the study and analysis of creativity from the educational point of view. Considering their plans, objectives, content, and educational facilities, educational systems have an important role in the activation or suppression of creative abilities in individuals. Therefore, most communities have focused their attention since long ago on the revision and modification of the curricula and educational plans with the purpose of helping the development of creative abilities in children and adolescents. Today's students are more technologically capable and expect the educational experience to acknowledge this. The old tried and true methods may no larger be effective because current technological development are changing the learning process [1]. Simplicio stated that teachers must be willing to utilize different strategies, methodologies, and approaches to instruction; they must be willing to change their methods and criteria of evaluation.

A number of authors have suggested attributes of innovative teaching and identified personal characteristic of

Manuscript received July 9, 2013; revised October 25, 2013.

Afzal Sadat Hosseini is with University of Tehran, Iran (e-mail: afhoseini@ut.ac.ir). innovative teachers [2], [3]. A creative teacher is seen as the one who is consistently curios and constantly seeks out new ways to improve her or his teaching abilities. In addition to improving their skills, teachers must also increase their understanding of student needs and preferences and constantly seek out new ways for transmitting knowledge [1].

However, as teacher review promotional materials from creativity training programs, they should seek those programs that have the strongest research and evaluation bases to ensure that the desired effect has been documented. Whatever programs are used or strategies are taught, teachers should be aware that transfer from the context in which they were taught to other situations will likely not occur unless they take time to assist students with seeing and practicing other application [4].

Fatt (2000) assert that great teaching requires an open relationship between the teacher and students. Teachers should provide students with opportunities to have input into classes. This interaction between teacher and student helps the teacher identify the particular abilities and needs of each student. Ritchart (2004) also emphasized the importance of teacher - student interaction. In a truly creative classroom, the students are doing more than learning the curricular content. Innovative teachers create opportunities for student expression, such as open - ended assignments or student led discussions. Ritchart (2004) identified two areas of creative teaching - curriculum and instruction. According to him, creative teachers look to shape curriculum and present it in new, more productive ways. A creative approach to curriculum involves finding new topics for students to explore. A creative approach to instruction involves finding new approaches or ways of presenting information. The creative teacher will find multiple methods to engage students [5].

Studies on creative teaching found that teachers placed a great emphasis on their interpersonal relationship with students [6]-[8].

Creativity training programs have general support among students, educators, and parents [9] with what Saxon, Treffinger, Young, and Wittig (2003) call "customer satisfaction " thought in a study of one competitive program, teachers were more supportive than students, and younger students were more positive than older students [10].

Iranians, too, need a fundamental and profound revolution in our educational system in order to revive this ability, which itself requires an awareness of our present situation so that we can plan for enhancing our educational system.

Evaluation (in a scientific manner) is a basic academic process which can strengthen or weaken the innovation. In all sections being positively fulfilled an institutionalization may follow. That means an agreement for a takeover into education curriculum [11]. 
Considering the educational system in our country, we find that there is still a long way to the situation that can pave the way for the development of creativity in children and adolescents. Therefore, research into different educational elements and their roles in nurturing creativity in students is of great importance. Teachers, from among effective educational elements and factors, play a crucial role. The author has proved, via several research studies, that teachers are capable of replacing their previous teaching methods with a creative approach, in spite of the serious obstacles such as a stereotyped curriculum, if they are provided with a suitable educational structure [12], [13].

\section{A. Creativity as an Educational Approach}

Runco and Chand [14] stated that a creative thinking is one that leads to innovative thoughts, solutions, and insight, which requires interactive components and processes, as presented in the following diagram.

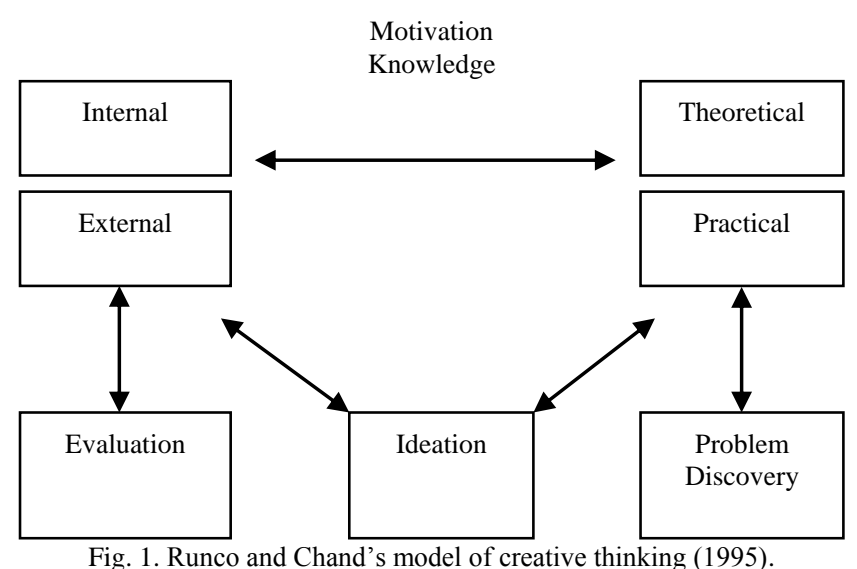

Runco and Chand tried to represent the complex structure of creative thinking and creativity through this pattern. They stressed the importance of knowledge and motivation in developing creative thinking. Theoretical knowledge is simple information that creative thinking gets involved with, whereas practical knowledge is the strategic thinking that Runco and Chand call Meta cognitive ability.

Runco and Chand's study shows that motivation, especially internal motivation, is of importance in discovering the problem. Motivation increases when the student is free to choose the tasks to be performed, as this makes the task meaningful to the student. Runco and Chand suggest that instructors allocate a lot of time to the problem-related skills, because they are no less important than problem solving itself and, in doing so, external motivations are utilized to nurture internal motivations. They emphasized that motivation depends upon cognitive and Meta cognitive processes such as recognition.

\section{B. Creativity Education Program in Iran}

Considering the key role of teachers in nurturing students' creativity, the author established creativity education program for teachers $(2002,1998)$. During that program, the teachers trained 70 hours. First, they got familiar with the nature and essential concepts of creativity in a 15-hour educational workshop, and then they learned methods of creativity education in a 25 -hour course, and applied the methods in their classrooms. The creativity growth model which was establish the basis of creativity theories in 1999 by the researcher, was thought in a 30-hour educational workshop, and the efficiency of the model in increasing the skills of creative teaching was tested.

This study evaluated the effect of creativity education program on knowledge, attitude and skills of teachers. The paper only addresses the effect of the creativity education program in general, and creativity growth model in particular, on the teachers' training skills. However, it is necessary to explain the creativity growth model in classrooms.

Creativity growth model:

Teacher performance can be evaluated from different points of view. Herein, we discuss five essential aspects of teacher performance:

- Contextual-social

- Affective- cognitive

- Mental

- Educational

- Physical aspects.

The social structure of classes has a deep effect on learning process. Having the security feeling is the primary condition for a creative classroom, since students should be able to ask any question and participate in discussions without being worried. The mutual respect of teacher and student result in improvement of self-confidence in students. Moreover, as was mentioned above, a fundamental characteristic of creative individuals is that they are highly self-confident.

Furthermore, if the evaluation is qualitative, and its goal is to make the student aware of what he/she has done, its negative effects are reduced. Competition will result in the feeling of humility in students. Hence, it is necessary to take advantage of intra-individual completion; for example the competition of each individual with him/herself, instead of inter-individual competition.

The existence of freedom of thought, speech and, movement are necessary to provide a creative classroom.

The affective-cognitive structure: Researchers consider the existence of affective-cognitive backgrounds essential for creativity growth [15]-[17].

Curiosity, involving ambiguity and dreams, and ability to take risk are the most important factors in a creativity-making affective-cognitive structure. Providing the opportunity for observation, testing, and searching the surrounding environment, and experiment is essential. By sensitizing students to different scientific and social problems, a competent teacher can play a crucial role in this concern. Rational risk taking is accompanied by test and consideration of new and unusual methods. Additionally, involving complexity and enjoying this complexity is important in creativity growth of children. As was mentioned in the previous section, dreams can also play an important role in training. Traditional methods emphasize direct transmission of knowledge and maintain these processes through inflexible structures which limit the engagement of learners in innovation, discovery and mental growth. Problem-solving and inquiry oriented approaches on the other hand, offer opportunities for exploring and discovering complexities, involving learners with the process of learning, and enhancing internal motivation [18].

Although the appropriate mental structure for creativity 
growth is not only considering the divergent thinking, considering the shortcomings in divergent thinking it is necessary to prompting this ability. If teachers value unusual ideas, they can promote their students' innovation ability. Many innovations and inventions have begun an unusual and strange question. Therefore, should encourage the unusual and seemingly irrational questions and responses of students.

Besides, if students are asked to focus on different aspects of a problem, the possibility of finding numerous different questions is increased. The quality of questions proposed by teacher has a determining effect in this regard and can lead to higher flexibility in students. By enhancing the quantity besides the quality, a teacher can increase the students' flexibility.

Educational-teaching structure: It is one of the most important aspects of teacher performance. By making use of creative methods and strategies of education, a competent teacher can creatively teach even inappropriate contents, and provide a creative space in the classroom.

When teacher transfers knowledge to her/his students by combining it with unique ways or new process in order to attain effective results it is called creative methods [19].

After getting familiar with the different aspects that can be effective in maintaining a creative atmosphere in classrooms, and active and creative education, different examples in various courses are provided in terms of different aspects and structures. In the final section, some examples will be provided.

\section{Objective of the Study}

Evaluating the effect of creativity education program (creativity growth model) in providing the skills of creative teaching was one of the main objectives of the study.

\section{Education Skill}

Education is defined as the interaction between the teacher and student in order to learn and behavioral change. The skills of creative teaching were the skills which provide the opportunity required for students' creativity education. The skills were then evaluated using a questionnaire).

\section{E. Research Hypothesis}

Creativity education program will lead to an increase in creative teaching skills of teachers.

\section{F. Samples and Study Population}

Study population was all teachers of primary school, in the 19 education regions of Tehran. 120 teachers were randomly selected from regions $2,6,9,13$, and 16, out of which 60 teachers were randomly assigned to experiment group and 60 to the control group.

\section{G. Data Collection Tool}

The questionnaire to evaluate the skills contained 35 items, and was designed according to a 5-point Likert scale. The reliability of the questionnaire was determined to be $87 \%$ according to internal consistency of Cronbach alpha test. Moreover, considering the good theoretical basis and consensus of specialist, the face and content validity of the questionnaire was confirmed.

\section{MethodOLOGY}

Both experiment and control groups filled the questionnaires. Afterwards, the experiment group participants attended a 70-hour educational course in one month. Then, after acquisition of skills, the experiment group members put the skills into practice, and in the next session reported their performance, and received feedbacks.

Subsequently, the two groups were given the final test to reveal the effect of creativity education program on teachers' skills.

Results:

To test the research hypothesis, $T$-test was used for independent groups.

The following Table I demonstrates the results of independent $T$-test between the experiment and control groups in terms of skill.

TABLE I: MEAN COMPARISON OF SKILL TEST OF EXPERIMENT AND CONTROL GROUPS

\begin{tabular}{|c|c|c|c|c|c|}
\hline Test & Test & Mean & Sum & S.D. & $\begin{array}{l}T \\
\text { value }\end{array}$ \\
\hline \multirow[t]{2}{*}{ Before course } & Experiment & 59.62 & 60 & 10.65 & 0.11 \\
\hline & Control & 60 & 61 & 14.2 & \\
\hline \multirow[t]{2}{*}{ After course } & Experiment & 68.64 & 60 & 10.57 & 2.53 \\
\hline & Control & 60.62 & 61 & 14.1 & \\
\hline
\end{tabular}

$T=2.65$

TABLE II: DID THE EDUCATIONAL COURSE INCREASE YOUR TEACHING SKILLS?

\begin{tabular}{|c|c|c|c|c|c|c|}
\hline Statistical index & Extremely & Quite a bite & Moderately & Slightly & Rarely \\
\hline Frequency & 53 & 7 & 0 & 0 & 0 \\
\hline Percentage & 88.3 & 11.7 & 0 & 0 \\
\hline
\end{tabular}

Table II provides the results of independent T-test between the experiment and control groups in terms of skill. Concerning the results at the D.F. $=119$ and the confidence interval $=99 \%$, the $T$-value determined to be 2.65 , which is greater than the $T$-value of the statistical table $(\mathrm{T}=2.33)$. Therefore, the experiment and control groups are not significantly different in terms of skill. As can be observed in this table, the T-value obtained before the course $(T=0.11)$ was smaller than the T-value of the statistical table, which implies that the two groups were not significantly different before the test. However, in the post-test, the obtained $T$-value $(T=2.53)$ was greater than the $T$-value of the 
statistical table, indicative of a significant difference.

\section{DISCUSSION AND CONCLUSION}

As the results were shown, the educational program and creativity growth model increased the skills of creative teaching in teachers.

One reason for the success of the model was considering the different effective elements in education and teaching. Considering the affective, cognitive, social, and physical aspects of the classroom besides the mental aspects provide a suitable opportunity for teachers to be able to employ creative teaching methods more appropriately.

Responding an open-ended question on the effect of the model on their teaching skills, they considered that after getting familiar with this model, they promoted a creative atmosphere in their classrooms. This resulted in the participation of students in classes and the class activities with a higher motivation, such that students preferred to stay in their classroom even in the break time, and continue their activities.

All teachers stated that by attending the course, their classes moved away from teacher-centered classes toward the classes on the basis of learners' activities, and this made students very enthusiastic.

"By passing the course, my class was completely moved away from teacher-centered class, and students take control of the class. The class became such sincere and highly motivated that students did not pay attention to the break time."

"Learning lessons by creative performance was very joyful for all students, even for slow-witted ones. Employing this method, all were very interested in learning, and participate in lessons and discussions."

"This course created a new view point toward the way of teaching ... a vivid and enthusiastic relationship is created between teacher and student, such that students are thirsty for finding the answers."

Teachers state that:

I find the students thirsty for finding the answers.

My classroom is full of motivation.

Now, I am trying to employ more innovation in teaching lessons.

The students do not care for the break time anymore.

Parents of students explain that their children are got better toward the nature and their surroundings.

Bashful and stuttering students became active in class, and they can explain what they want.

The things I learned from the students are two times of the things they learned from me in previous years.

This method evolved the children and introduced me as a successful teacher.

Now, the students are able to imagine and create what I say.

In general, from the teachers' point of view, the effects of this course were as follows:

\section{A. Teacher}

- Moving away from the frameworks and clichés.
- Moving away from teacher-centered classes.

- Enjoy ability of teaching for teachers.

- Changing the attitude toward teaching and managing the classroom.

- Using qualitative evaluation methods.

- Increasing the power of thought and innovation.

- Employing various heuristic methods.

- Providing psychic security in classrooms, such that students can ask any questions.

- Creation of a deep respect and emotional relationship with the students.

- Elimination of competition, and not comparing the students with each other.

\section{B. Students}

- Thinking beyond the class hours.

- Enjoying the class hours.

- Students' activity.

- Proposing various answers.

- Increased self-confidence.

- Sincere cooperation among students.

- Deeper learning of lessons.

- Better social relationship.

- Improving the imagination and creation abilities.

\section{REFERENCE}

[1] J. S. Simplicio, "Teaching classroom educators how to be more effective and creative teachers," Education, 2000, ch. 3, pp. 675-680.

[2] J. P. T. Fatt, Fostering creativity in education, 2000, ch. 3, pp. 744-757.

[3] R. Ritchart, "Creative teaching in the shadow of the standard," Independent School, ch. 1, pp. 32-40, 2004.

[4] S. L. Hunsaker, "Outcomes of Creativity Training Programs," Journal of Gifted Child Quarter, vol. 49, no. 4, pp. 291-299, 2005.

[5] K. Jaskyte, H. Taylor, and R. Smariga, "Student and Faculty Perceptions of Innovative Teaching," the Creativity Research Journal, vol. 21, no. 1, pp. 111-116, 2009.

[6] J. S. Dacey, Fundamentals of creative thinking, MA: Lexington, 1989, ch. 2, pp. 154-155.

[7] J. Horng et al., "Creative teachers and creative teaching strategies," International Journal of Consumer Studies, vol. 29, no. 1, pp. 352-358, 2005.

[8] B. Lynch, "Innovative teaching in a higher education establishment How extraordinary?" Journal of Further and Hifher Education, vol. 25, no. 2, pp. 175-194, 2001.

[9] N. A. Roell, "The Odyssey of the Mind school program in participating Texas middle and junior high schools: Perceptions of administrators, OM coaches, and team members regarding program implementation and goals," International journal of education, vol. 63, no. 7, pp. 140-143, 2002.

[10] M. Frasier, S, Winstead, and J. Y. Lee, "Is the Future Problem Solving Program accomplishing its goals," Journal of Secondary Gifted Education, vol. 8, no. 1, pp. 157-163, 1997.

[11] M. F. Hertsch, "Innovative and Organized Approaches to Foreign Language Teaching," Cypriot Journal of Educational Sciences, vol. 8, no. 1, 2013.

[12] A. Hosseini, "Investigating the impact of the creativity teaching program on teacher's knowledge attitude and skills," Quarterly Journal of Educational Innovations, vol. 22, no. 1, pp. 104-131, 2008.

[13] A. Hosseini, The creativity and its developmental methods, Tehran: Astan Qods Press Iran, 1998, ch. 5, pp. 104-108.

[14] M. A. Runco and I. Chand, "Cognition and creativity," Educational psychology review, vol. 7, no. 1, pp. 243-26, 1995.

[15] F. E. Williams, Creativity project, Macalester College Saint Paul Minnesota, 1970, ch. 2, pp. 140-145.

[16] E. Paul. "Torrance, Fostering Academic creativity in gifted students," Eeic EC Digest, U.S.A, 1990, ch. 3, pp. 220-223.

[17] R. J. Sternberg and S.W. William, "How to develop student creativity," in Proc Association for supervision and curriculum development, Virginia, 1997, pp. 65-67. 
[18] A. Hosseini, "Professor's evaluation of creative education in universities and their impact on university students' learning," Journal of Theory and Practice in Education, vol. 6, no. 2, pp. 179-190, 2010.

[19] R. C. Reilly, L. F. Bramwell, and N. Kronish, "A Synthesisof Research Concerning Creative Teachers in a Canadian Context," Journal of Teaching and Teacher Education, vol. 27, no. 1, pp. 533-542, 2011.

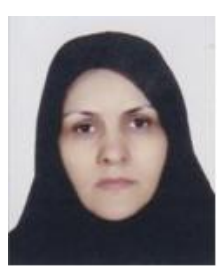

Afzal Sadat Hosseini was born in Yazd, Iran. She received B.S. degree in educational management from Faculty of psychology \& Education science of Esfahan university, Esfahan, Iran in 1987, and Ph.D. degree in philosophy of education in tarbiat modares faculty of Humanities, Tehran, Iran, 1997.

She then joined Faculty of Psychology \& Education Science, Tehran, Iran, as a Professor. From 1998 until 2013 he was appointed as an Education And Creativity Researcher in Faculty of psychology \& Education science of Tehran, Iran and ASSOCIATE PROFESSOR in Department of psychology \& Education, Tehran, Iran. she is specialized in Creativity in preschool And Academic Education, Thinking skills, Effective Teaching Strategies, Techniques of Creativity.

Dr. Afzal Sadat Hosseini has served, and is serving, as a member of Faculty of psychology \& Education science, co-founder of entrepreneurship field university of Tehran (2004 - 2006), member of board of editors, quarterly journal of creativity and innovations (QJCI), Member of council of center of develop creativity in university of Tehran. She was awarded as a Writer of Top Book of Year that's name: Nature of creativity and its developmental strategies from Jahad of Tehran University in 1998. 